\title{
CANULAÇÃO CECAL EM EQUINOS
}

\author{
Andrea Del Pilar Uribe Diaz, ${ }^{1}$ Aureo Evangelista Santana, ${ }^{2}$ \\ Carlos Augusto Araujo Valadẽo² e Adriana Helena de Souza ${ }^{3}$ \\ 1. Departamento de Clínica e Cirurgía Veterinária, Área de Fisiopatologia Cirúrgica. \\ E-mail: apilaritau@hotmail.com \\ 2. Professor doutor, FCAV/UNESP \\ 3. Departamento de Clínica e Cirurgía Veterinária, FCAV/UNESP.
}

\section{RESUMO}

As doenças gastrointestinais têm participação importante nas alterações sistêmicas observadas nos equinos. Assim, inúmeros estudos têm sido realizados para o melhor entendimento desses processos, exigindo a implantação de cânulas. Neste trabalho, descrevem-se técnica cirúrgica para implantação de cânula cecal em equinos e as principais alterações pós-cirúrgicas. Utilizaramse nove equinos adultos mestiços, nos quais o procedimento cirúrgico foi realizado em duas etapas. Foi feita uma incisão na região paracostal direita e fixado o aspecto dorsal do ceco à parede abdominal, no primeiro tempo operatório. Na segunda etapa cirúrgica, procedeu-se à incisão da parede do ceco, introduziu-se a cânula no lúmen cecal, fixando-a à parede abdominal. A técnica mostrou-se viável quando realizada em duas etapas operatórias. As cânulas de látex foram bem toleradas pelos pacientes, permitindo a obtenção de conteúdo cecal num período de 120 a 160 dias, sendo consideradas adequadas para fins experimentais.

PALAVRAS-CHAVES: Canulação intestinal, ceco, cecostomia, equinos.

\section{ABSTRACT}

\section{CECAL CANNULA IN HORSES}

Gastrointestinal diseases play an important role in the systemic alteration in horses. Several studies have been performed in order to better understand these processes. For these studies, to place a cannula inside the animal is a requirement. This study aimed to describe the surgical technique to place a cecal cannula in horses and the major postoperative changes. Nine adults and mixed breed horses were used in this study. The surgical procedure was performed in two steps. Primarily, through an incision in the right

KEYWORDS: Cecostomy, cecum, horses, intestinal cannulation.

\section{INTRODUÇÃO}

Nos últimos anos, pesquisas foram desenvolvidos buscando o melhor entendimento dos processos mórbidos primários e secundários à cólica equina. Di- costal region, the dorsal segment of the cecum was sutured against the abdominal wall. In the second procedure, after the incision in the segment of the cecum, a canula was placed in the cecal lumen and sutured against the abdominal wall. This technique was viable when performed in two separated surgical procedures. The latex cannulas were well accepted by the horses, samples from the cecum could be collected throughout a period from 120 to 160 days, being considered appropriated for experimental procedures.

versos estudos experimentais têm sido realizados com o intuito de identificar fatores de risco relativos às possíveis causas primárias. Neste contexto, o estudo das afecções do aparelho digestório por meio de ensaios experimentais passou a ser alternativa de compreensão 
da síndrome. A implantação de fístulas e cânulas nos segmentos do trato gastrointestinal tem permitido obter maiores informações sobre a evolução dos distúrbios toxicoalimentares, frequentemente observados em alguns casos de cólica (LACERDA NETO et al., 1989). As cânulas intestinais têm sido uma ferramenta valiosa no estudo das funções digestivas das diversas espécies. A facilidade na colheita de amostras seriadas, em diferentes porções estratégicas no trato intestinal, permite a análise e a avaliação clínico-patológica de inúmeras variáveis, não factíveis por outros métodos (KOMAREK, 1981a). A fistulação das diversas porções dos intestinos dos equinos tem merecido a atenção de muitos pesquisadores, entretanto, observa-se uma contribuição reduzida sobre o assunto, principalmente em relação à evolução pós-operatória.

Assim, idealizou-se o presente ensaio com o intuito de descrever as etapas da técnica cirúrgica, para a canulação do ceco em equinos, e as principais alterações clínico-laboratoriais, decorrentes desta.

\section{MATERIAL E MÉTODOS}

Foram utilizados nove equinos adultos (três machos e seis fêmeas), sem raça definida, clinicamente hígidos e sem alterações gastrointestinais aparentes, com idades variando entre 3 e 6 anos, pesando entre 240 e $340 \mathrm{~kg}$ e com escore corporal entre 3 e 4 (SPEIRS, 1999). Para a adaptação alimentar, foram alojados em baias individuais, por duas semanas, em regime alimentar composto de $2 \mathrm{~kg}$ de ração concentrada comercial, ${ }^{1}$ feno de Cynodon dactilon L. ("Coast cross") e água ad libitum. Em período anterior à intervenção cirúrgica, submeteram-se os animais a jejum alimentar por oito horas. A cânula a ser implantada no ceco dos equinos constituiu um modelo simples em forma de $\mathrm{H}$ para abomaso, ${ }^{2}$ flexível, confeccionada em látex (borracha natural) com as seguintes dimensões: $27,9 \mathrm{~mm}$ de diâmetro externo e $25,4 \mathrm{~mm}$ de diâmetro interno; $81 \mathrm{~mm}$ de diâmetro na base e $79 \mathrm{~mm}$ de comprimento. Inclui-se, ainda, um anel de vedação aplicado externamente, para ajuste do espaço entre a base da cânula e a parede abdominal. O lúmen da cânula é fechado com um tampão cônico removível, confeccionado em látex (Figura 1).

1 Tec Horse - Purina ${ }^{\circledR}$ - Paulínia, SP

2 KEHL Ltda. São Carlos, SP

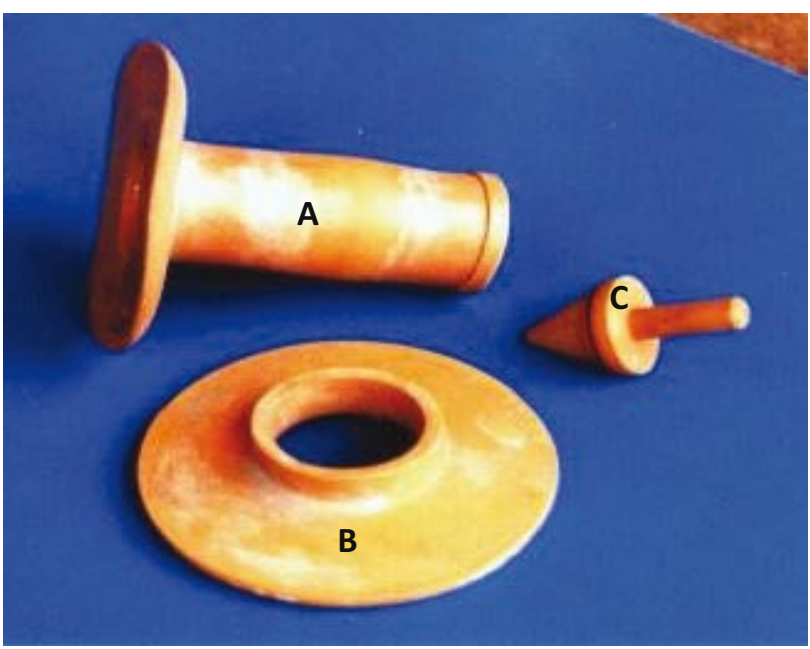

FIGURA 1. Cânula para abomaso em forma de "H". Corpo da cânula (A), anel de vedação (B) e tampão cônico removível (C).

Os equinos foram mantidos em apoio quadrupedal, sendo-lhes aplicados maleato de acepromazina ${ }^{3}$ $(0,05 \mathrm{mg} / \mathrm{kg})$, por via intravenosa (IV), e decorridos quinze minutos, pela mesma via, cloridrato de xilazina ${ }^{4}$ $(0,5 \mathrm{mg} / \mathrm{kg}$ IV $)$. Subsequentemente foi realizada a tricotomia do flanco direito e, após antissepsia, procedeu-se à anestesia local infiltrativa em " $L$ " invertido, na fossa paralombar direita. A primeira linha de infiltração foi realizada $3 \mathrm{~cm}$ abaixo dos processos transversos das vértebras lombares, paralela ao eixo da coluna vertebral $(10 \mathrm{~cm})$. A outra linha de infiltração de anestésico (10 $\mathrm{cm})$ foi aplicada paralelamente a dois centímetros da última costela, empregando-se cloridrato de lidocaina ${ }^{5}$ $2 \%$ no tecido subcutâneo, bem como nos planos musculares mais profundos. Decorridos quinze minutos, aplicou-se cloridrato de meperidina ${ }^{6}(2 \mathrm{mg} / \mathrm{kg})$ por via intramuscular (IM). Realizou-se antissepsia do campo operatório e, posteriormente, aplicou-se um pano de campo fenestrado sobre a região. A incisão de pele foi praticada a uma distância intermediária entre a tuberosidade ilíaca e a última costela, ventralmente ao músculo longo dorsal, abrangendo 6 a $8 \mathrm{~cm}$ na pele, tela subcutânea, músculos oblíquos abdominais externo e interno, músculo transverso do abdome e

\footnotetext{
3 Acepran 1\% ; E.H.G. Agrofarma; Mogi Mirim, SP

4 Coopazine; Schering-Plough S.A.; Cotia, SP

5 Xilestesin 2\% (sem vasoconstritor), Cristália Produtos Químicos e Farmacêuticos Ltda., Itapira, SP

6 Dolosal, Cristália Produtos Químicos e Farmacêuticos Ltda., Itapira, SP.
} 
peritônio. A hemostasia foi realizada com pinçamento e angiotripsia dos vasos de menor calibre. Nos vasos de maior diâmetro (artéria e veia hipogástrica), procedeu-se à ligadura com fio categute ${ }^{7}$ cromado $n^{0}$. 0 . Na sequência, introduziu-se a mão na cavidade abdominal, identificou-se o corpo do ceco por palpação e, mediante tração da tênia lateral, exteriorizou-se o órgão (Figura 2).

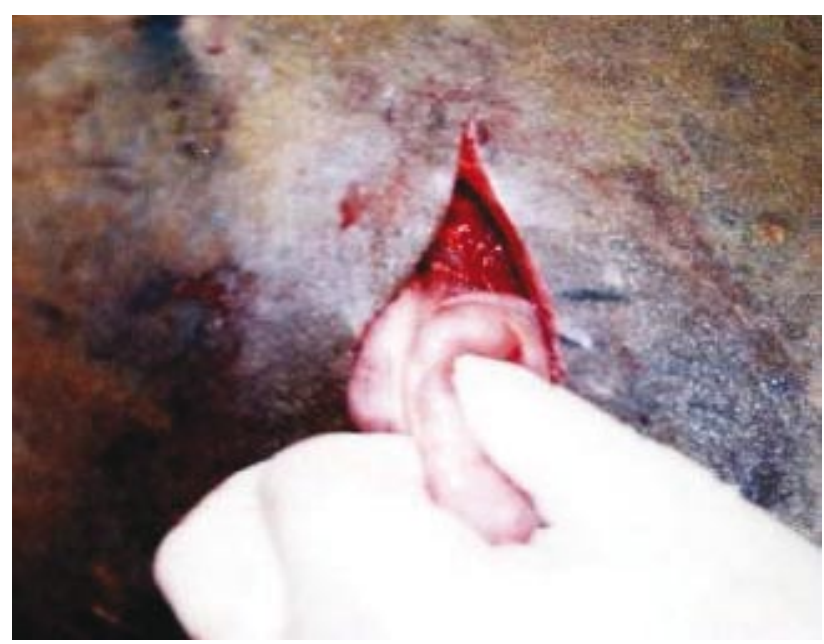

FIGURA 2. Identificação do ceco por palpação da tênia lateral.

Na sequência, fixou-se o ceco à borda caudal da incisão, na tela subcutânea ancorada na fáscia dorsal do músculo oblíquo abdominal externo, por meio de sutura contínua simples, aplicada sobre a tênia lateral, empregando-se categute cromado $n^{\circ} 2$ (Figura 3). Em ato contínuo, a porção do ceco, anterior à tênia lateral, foi exposto e fixado por meio de sutura seromuscular com categute fortemente cromado $\mathrm{n}^{\circ} 4$, à borda cranial da incisão cirúrgica, fáscia dorsal do músculo oblíquo abdominal externo. Ao término da sutura lavaram-se a superfície do ceco exposta e o campo operatório com solução de cloreto de sódio $0,9 \%{ }^{8}$. Em seguida, fixou-se sobre a ferida, por meio de sutura com fio de náilon $\mathrm{n}^{\circ} 45$ monofilamentar agulhado, uma bandagem composta por compressas de gaze estéreis embebidas em solução de sulfato de neomicina ${ }^{9}$ a $10 \%$. A incisão

7 Fio de Catgut, Shalon Fios Cirúrgicos Ltda., São Luiz de Montes Belos, GO.

8 Solução de Cloreto de Sódio a 0,9\%, Laboratório Sanobiol Ltda., São Paulo, SP.

9 Neocolin, Vansil, Industria, Comércio e Representações Ltda., Descalvado, SP. de pele permaneceu aberta e ao redor dela aplicou-se uma mistura de fenitrothion, ${ }^{10}$ violeta de genciana e essência de citronela, para exercer ação repelente. Foram realizados curativos com solução fisiológica com sulfato de neomicina a $10 \%$ e reaplicação de repelente ao redor da ferida cirúrgica, uma vez ao dia, durante os cinco dias subsequentes.

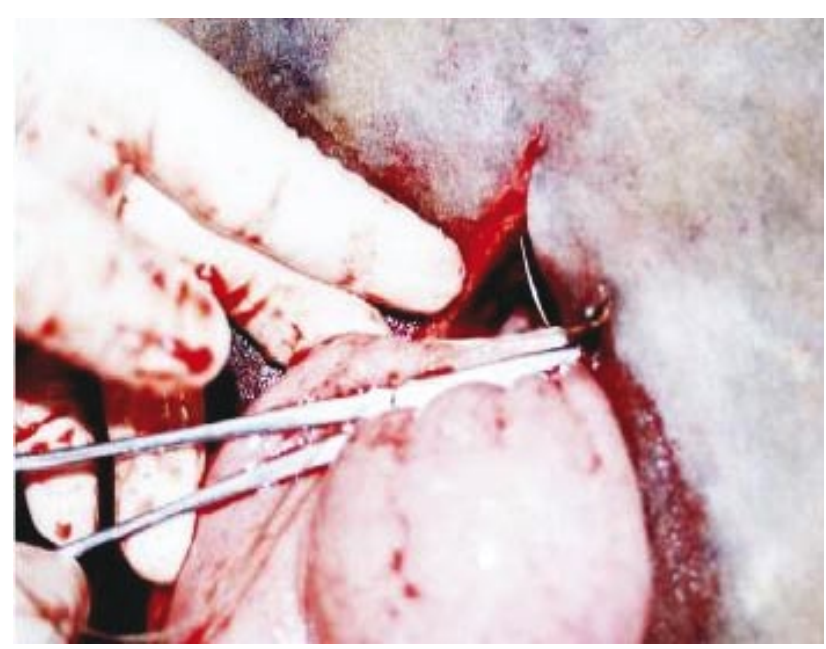

FIGURA 3. Fixação do ceco à parede abdominal.

Decorridos cinco dias da fixação do ceco à parede abdominal (tiflopexia), foi administrado maleato de acepromazina $(0,05 \mathrm{mg} / \mathrm{kg}$, IV) e quinze minutos após aplicou-se cloridrato de xilazina $(0,3 \mathrm{mg} / \mathrm{kg}$, IV $)$ aos animais. Retirouse a bandagem, procedendo-se à lavagem da pele adjacente à incisão com solução de cloreto de sódio a $0,9 \%$ e sabão neutro. Na sequência, foi realizada antissepsia da serosa do ceco, anteriormente fixada. Procedeu-se à anestesia local infiltrativa com cloridrato de lidocaina $2 \%(20 \mathrm{~mL}$ por animal), nas bordas da ferida cirúrgica. Realizou-se uma fenestração do ceco fixado anteriormente à parede abdominal, por incisão circular de aproximadamente $2 \mathrm{~cm}$ de diâmetro, ressecando-se um segmento circular da parede cecal (Figura 4). Através desse orifício, procedeu-se à introdução da cânula, cuja base com uma aba complacente foi dobrada para permitir a passagem através do neo-óstio (Figura 5A). Na sequência, foram colocados o anel de vedação (Figura 5B) e o tampão cônico para obliteração da luz da cânula (Figura 5C).

10 Cidental, Mogivet Produtos Agro Veterinários Ltda., Monte Mor, SP. 


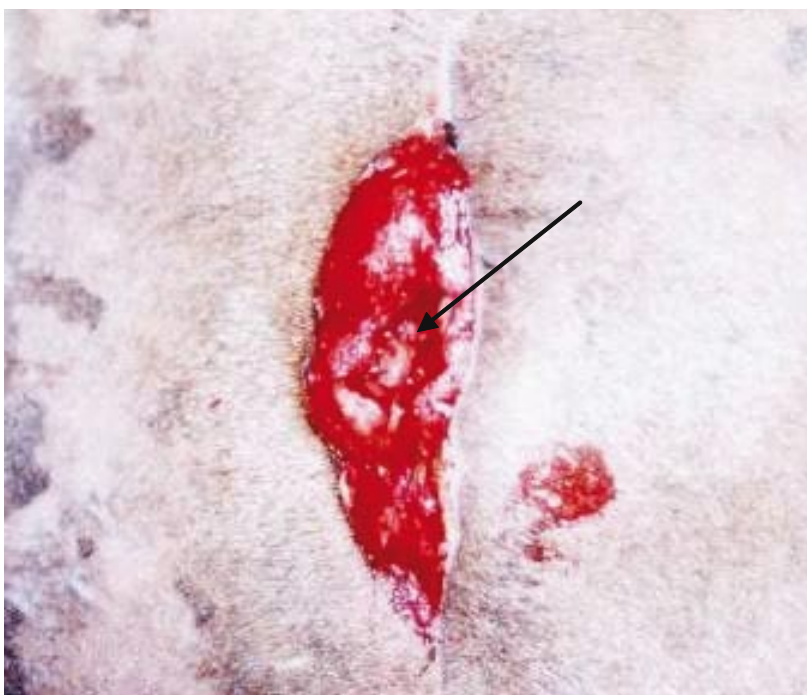

FIGURA 4. Incisão circular na superfície exposta do ceco (seta).

Finalmente, foi realizado curativo local e aplicou-se pomada repelente ao redor da cânula, procedimento que foi repetido uma vez ao dia, durante sete a dez dias. A avaliação clínica dos equinos constou de aferição de frequência cardíaca ( $\mathrm{FC}$, em bat/min), por meio de estetoscópio, ${ }^{11}$ bem como de frequência respiratória (FR, em mov/min), pela movimentação do gradil costal, da temperatura retal (TR, em $\left.{ }^{\circ} \mathrm{C}\right)$, mensurada por termometria clínica convencional, ${ }^{12}$ e da coloração das mucosas determinada por inspeção. A motilidade intestinal foi avaliada mediante o uso de estetoscópio, auscultando-se os quatro quadrantes da cavidade abdominal durante um a três minutos, constando a presença de borborigmos e a abertura e fechamento da válvula ileocecal. Procedeu-se ao exame físico imediatamente antes de cada etapa cirúrgica e às 12, 36, 72 e 120 horas seguintes. Os animais foram observados até completar 160 dias, após a colocação da cânula.

11 Estetoscópio Classic I S.E., Littman, EUA

12 Termômetro Veterinário, Becton, Dickinson Ind. Cirúrgicas Ltda, Juiz de Fora, MG.

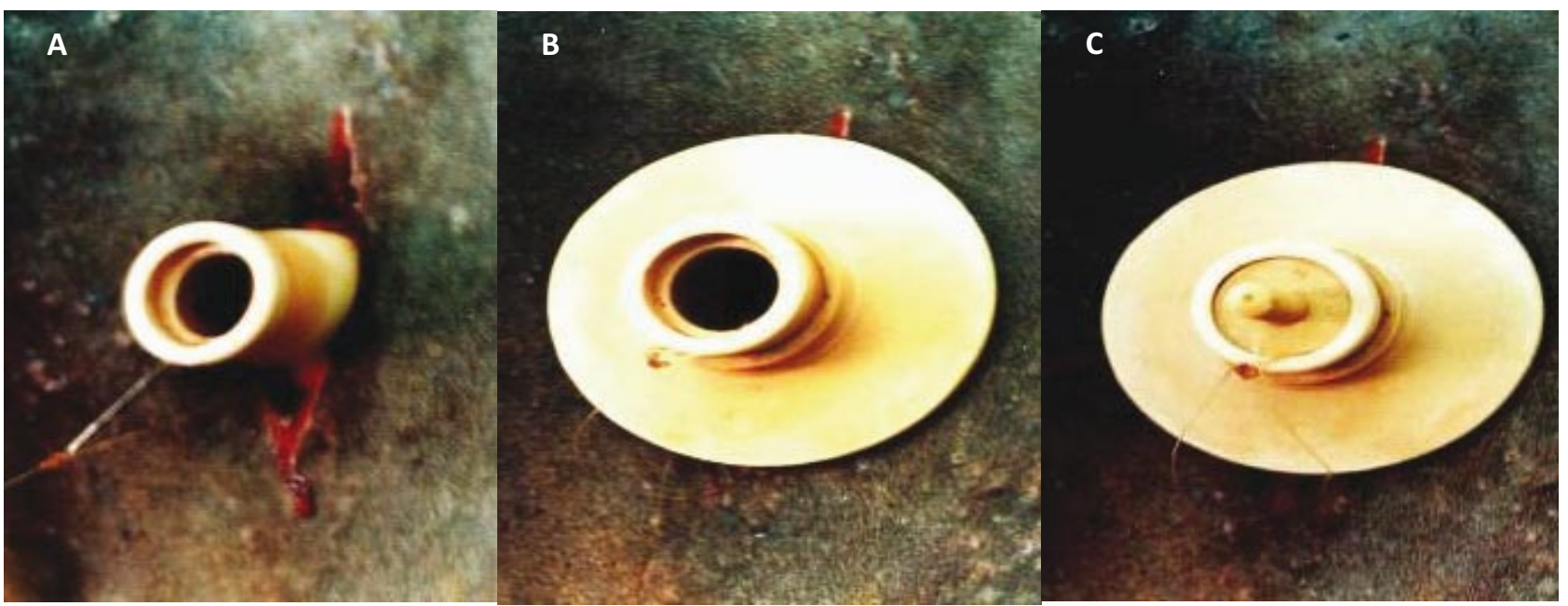

FIGURA 5. Implantação cirúrgica da cânula de látex, colocação do corpo da cânula (A), ajuste do anel de vedação (B), colocação do tampão cônico (C)

Submeteram-se os dados obtidos nas fases experimentais, para cada parâmetro estudado, à análise estatística mediante o emprego do programa de computador Sigma Stat for Windows. O teste de normalidade de Kolmogorov-Smirnov foi usado para verificar a distribuição normal dos dados. Para a comparação das médias ao longo do período experimental, utilizou-se a análise de variância de uma via ANOVA seguida pelo teste de Student-Newman-Keuls. As diferenças foram consideradas estatisticamente significativas para $\mathrm{p} \leq 0,05$. 


\section{RESULTADOS E DISCUSSÃO}

Decorridas doze horas da primeira etapa cirúrgica, foram observados sinais de desconforto abdominal discreto, caracterizados por olhar para o flanco e cavar o solo, em todos os equinos. Constatou-se que a cânula para abomaso em forma de $\mathrm{H}$ se acomodou satisfatoriamente no lúmen cecal, sem dificultar clinicamente o trânsito da ingesta num período variável entre $120 \mathrm{e}$ 160 dias. Decorridos oito dias da canulação do ceco, a evolução da ferida cirúrgica foi satisfatória.

Em todos os cavalos, o processo de epitelização das bordas do neo-óstio foi rápido e bem-sucedido, não sendo observados sinais macroscópicos de infecção ou presença de exsudato até o décimo dia. LOPES (2002) relatou a remoção de parte dos músculos envolvidos na incisão cirúrgica, com o objetivo de proporcionar espaço à cânula. No entanto, em estudo-piloto realizado previamente ao experimento, foi observado que esse procedimento ocasionava resposta inflamatória exacerbada. Por essa razão, optou-se por não realizar a remoção dos músculos, o que de fato permitiu registrar uma resposta inflamatória moderada nos tecidos adjacentes à ferida cirúrgica doze horas após a primeira etapa. O material flexível da cânula foi considerado apropriado e bem tolerado, quando em contato com os tecidos, corroborando os achados de KOMAREK et al. (1960), KOMAREK \& LEFFEL (1961), MARKOWITZ (1964) e LOWE et al. (1970). Esses autores relataram que cânulas feitas de material flexível são fáceis de serem implantadas no trato gastrointestinal dos equinos e se acomodam aos movimentos na região do flanco, reduzindo as agressões causadas por distúrbios mecânicos e consequentemente evitando ferimentos na mucosa cecal e na pele junto às bordas da fístula.

Diferentemente dos dados apresentados por LOPES (2002), neste estudo foi possível verificar que o jejum alimentar de oito horas foi adequado para a execução da tiflopexia, pois não se observou distensão abdominal, o que permitiu a manipulação do ceco. Verificou-se que o fio categute cromado $n^{\circ}$ 2 e o padrão de sutura simples contínua utilizados na fixação do ceco à parede abdominal foram eficientes, impedindo o extravasamento do conteúdo cecal para a cavidade abdominal, fato também constatado por LOPES (2002).
Aumentos significativos nas frequências cardíaca e respiratória, no tempo de preenchimento capilar e na temperatura retal, estão presentes em processos inflamatórios severos e são atribuídos a diversas causas (BONOUS, 1993; CARGILE et. al., 1995). No presente trabalho, não foram registradas alterações estatisticamente significativas nessas variáveis, o que leva a inferir que o quadro de desconforto abdominal leve observado doze horas após a tiflopexia pode estar associado a uma resposta inflamatória moderada desencadeada pelo procedimento cirúrgico. A coloração das mucosas constitui um excelente indicador do estado circulatório do animal. Nem sempre existe um padrão de coloração a ser considerado, porém as mucosas aparecem pálidas na fase inicial de qualquer alteração abdominal, para em seguida, na dependência da gravidade do transtorno, ficarem congestas (coloração vermelho intenso) e cianóticas nos casos terminais (THOMASSIAN, 1996).

Dos oito animais, somente um apresentou membranas mucosas ligeiramente congestas doze horas após a tiflopexia, achado clínico considerado isolado, já que 36 horas após o procedimento cirúrgico a coloração apresentou-se normal. A auscultação do abdômen é essencial para o exame clínico de animais portadores de desconforto abdominal. Os sons dos intestinos dos cavalos são claramente audíveis. A redução ou ausência dos borborigmos intestinais pode estar associada a múltiplos fatores (THOMASSIAN, 1996). Procedimentos cirúrgicos que envolvam segmentos intestinais específicos podem causar hipotonia ou atonia e, consequentemente, redução localizada dos borborigmos, o que justifica a diminuição da motilidade intestinal no quadrante dorsal direito, assim como a diminuição na frequência da descarga da válvula ileocecal doze horas após a tiflopexia, considerando o procedimento cirúrgico como o fator agressor.

\section{CONCLUSÃO}

Os procedimentos cirúrgicos realizados, em duas etapas, para implantação da cânula em forma de $\mathrm{H}$ no ceco de equinos através da fossa paralombar direita, se mostraram eficientes para exposição, manipulação, fixação e posterior canulação do segmento entre a base e o corpo do ceco. 


\section{REFERÊNCIAS}

BONOUS, D. I. Test your diagnostic skill. Compedium Continuing Education Veterinary Practice, v. 15, n. 4, p. 611-613, 1993.

CARGILE, J. L.; MACKAY, R. J.; DANKERT, J. R.; SKELLEY, L. Effect of treatment with a monoclonal antibody against equine tumor necrosis factor (TNF) on clinical, hematologic and circulatingTNF responses of miniature horses given endotoxin. American Journal Veterinary Research, v. 56, n. 11, p. 1451-1459, 1995.

KOMAREK, R. J. Intestinal cannulation of cattle and sheep with a T-shaped cannula designed for total digesta collection without externalizing digesta flow. Journal Animal Science, v. 53, n. 3, p. 796-802, 1981.

KOMAREK, R. J.; LEFFEL, E. C. Gas-tight cannula for rumen fistula. Journal Animal Science, v. 20, p. 782, 1961.

KOMAREK, R. J.; LEFFEL, E. C. Technique for the establishment of a rumen pouch. Journal Applied Physiology, v. 15, p. 161, 1960.

LACERDA NETO, J. C. Cólica eqüina: diagnóstico e tratamento. Jaboticabal: FUNEP, 1989. p. 1.
LOPES, M. A. F.; DEARO, A. C. O.; IAMAGUTI, P.; THOMASSIAN, A.; FIGUEIREDO, L. M. A. Aderências peritoneais em equinos: tratamento profilático com carboximetilcelulose. Ciência Rural, Santa Maria, v. 28, n. 3, Sept., 1998. Disponível em: $<$ http://www.scielo.br/scielophp?script=sci arttext\&pid=S010384781998000300012 \&ing $=$ en\& $\mathrm{nrm}=$ iso $>$ doi:10.1590/S010384781998000300012 .

LOPES, M. A. F. Hydration of colonic ingesta and feces in horses fid large grain meals or treatment enteral fluid therapy, saline cathartics and intravenous fluid therapy. 2002. Theses (PhD) - Virginia Polytechnic Institute and State University, Virginia, 2002. Disponível em: <http://www.vtech.com>. Acesso em: 26 out. 2004.

LOWE, J. E.; HINTZ, H. F.; SCHRYVER, H. F. A. A new technique for long-term cecal fistulation in ponies. American Journal Veterinarian Research, v. 31, p. 1109-1111, 1970.

MARKOWITZ, J.; ARCHIBALD, J.; DOWNIE, H. G. Experimental surgery including surgical physiology. 5. ed. Baltimore: Wiliams and Wilkins Company, 1964.

THOMASSIAN, A. Enfermidades dos cavalos. 3. ed. São Paulo: Livraria Varela, 1996. p. 463.

Protocolado em: 14 maio 2007. Aceito em: 5 fev. 2010. 